\title{
EVALUATION OF THE USE OF ANTIMALARIA MEDICINES IN HANURA HEALTH CENTRE PESAWARAN DISTRICT PERIOD JANUARY-DECEMBER IN 2018
}

\author{
Evaluation Of The Use Of Antimalarial Medicines In Hanura \\ Health Centre Pesawaran District period \\ January-December In 2018
}

\author{
Akhmad Rokiban ${ }^{1}$, Ramadhan Triyandi ${ }^{1}$, Karnila Sari ${ }^{2}$ \\ ${ }^{1}$ Pharmacy Study Programmes, Tulang Bawang University of Lampung \\ e-mail: rokiban81@utb.ac.id \\ HP. 082176547781
}

\begin{abstract}
Malaria is a public health problem in Indonesia, especially those living in isolated areas. This is published in Presidential Regulation No. 5/2010 concerning the National Medium Term Development Plan for malaria endemic areas, which are divided into high, medium and low endemic areas. High endemic if the API is greater than 50 out of 1,000 population in the provinces of Maluku, Papua, North Sumatra and East Nusa Tenggara. Moderate endemic if the API is 1 to less than 50 dari 1,000 population in the provinces of Aceh, Bangka Belitung, Jambi and West Nusa Tenggara. Low endemic if the API is 0-1 per 1,000 population in Kalimantan, Sulawesi, and parts of Java. This study aims to determine the evaluation of the use of antimalarial drugs with the characteristics of age, sex, and type of malaria plasmodium at the Hanura Public Health Centre based on the criteria of the right indication, the right drug, the right dose, the right interval of drug administration (4T). This research is a descriptive research with purposive sampling method. Collection of prescription data and medical records in January-December 2018. The results showed that in cases of Malaria based on age, the most common cases occurred in the age range of 56-65 years, amounting to $99.6 \%$, based on sex experienced in men by $77.41 \%$, based on body weight the most occurred at $41-59 \mathrm{~kg}$ at $45.16 \%$, based on the type of plasmodium experienced plasmodium vivax mostly at $84.95 \%$. Based on these data, it was concluded that the evaluation of the use of antimalarial drugs based on $4 T$ criteria was $100 \%$ accurate indication, $100 \%$ correct drug, $72.04 \%$ correct dose, $98.92 \%$ correct interval of drug administration.
\end{abstract}

Keywords: Malaria vivax, treatment, Puskesmas, $4 T$

\begin{abstract}
Malaria is a public health problem in Indonesia, especially those living in isolated areas. This is published in Presidential Regulation No. 5/2010 concerning the National Medium Term Development Plan for malaria endemic areas, which are divided into high, medium and low endemic areas. High endemic if the API is greater than 50 out of 1,000 population in the provinces of Maluku, Papua, North Sumatra and East Nusa Tenggara. Moderate endemic if the API is 1 to less than 50 dari 1,000 population in the provinces of Aceh, Bangka Belitung, Jambi and West Nusa Tenggara. Low endemic if the API is 0-1 per 1,000 population in Kalimantan, Sulawesi, and parts of Java. This study aims to determine the evaluation of the
\end{abstract}




\section{JFL \\ Jurnal Farmasi Lampung \\ Vol 9 No. 1 Juni 2020}

use of antimalarial drugs with the characteristics of age, sex, and type of malaria plasmodium at the Hanura Public Health Centre based on the criteria of the right indication, the right drug, the right dose, the right interval of drug administration (4T). This research is a descriptive research with purposive sampling method. Collection of prescription data and medical records in January-December 2018. The results showed that in cases of Malaria based on age, the most common cases occurred in the age range of 56-65 years, amounting to $99.6 \%$, based on sex experienced in men by $77.41 \%$, based on body weight the most occurred at $41-59 \mathrm{~kg}$ at $45.16 \%$, based on the type of plasmodium experienced plasmodium vivax mostly at $84.95 \%$. Based on these data, it was concluded that the evaluation of the use of antimalarial drugs based on $4 T$ criteria was $100 \%$ accurate indication, $100 \%$ correct drug, $72.04 \%$ correct dose, $98.92 \%$ correct interval of drug administration.

Keywords: Malaria vivax, treatment, Puskesmas, $4 T$

\section{INTRODUCTION}

World Malaria Report on 2015 states that malaria has attacked 106 countries in the world. Global commitment to the Millennium Development Goals (MDGs), placing efforts to eradicate malaria into one common goal, namely ensuring a healthy life and striving for the welfare of all people. (1)Malaria is still a threat to public health status, especially for people living in remote areas. This is reflected in the issuance of Presidential Regulation Number 5 of 2010 concerning the National Medium-Term Development Plan for 2010-2014 where malaria is a priority disease that needs to be tackled. (2)

Malaria infects about half a billion people in tropical and subtropical countries each year. The number of malaria cases in Indonesia in 2010 was 465,764 and in 2015 it had decreased to 209,413 cases. (3). According to Riskesdas 2018, the prevalence of malaria based on a history of blood tests in 2018 was $12 \%$, with the highest 2018 age group at $0-11$ months and $5-9$ years of age being $1.0 \%$ (4).

Some areas in Lampung Province are endemic areas that have the potential to develop malaria. The number of malaria endemic villages is 223 villages or $10 \%$ of all villages and the malaria morbidity rate per year is 1,000 people. The highest malaria morbidity rate in the Regency / City in 2015 was in Pesawaran District with the largest cases found in Lampung Province. (5)

The Pesawaran health office stated that the API in the Pesawaran district area for a period of 5 years $\left(\begin{array}{lll}2012 & -2 & 016\end{array}\right)$ fluctuated / not fixed. The Malaria Parasite Rate per 1,000 population is the morbidity rate for patients who are positive for malaria. The highest positive case of malaria based on the health center in Pesawaran District in 2016 was the Hanura Health Center, with the highest number of cases, namely 1,738 cases. (6)

The types of malaria parasites that play a major role in malaria transmission are Plasmodium falciparum and Plasmodium vivax. The type of malaria falciparum becomes severe malaria and is the only parasite that can cause microvascular disease. Symptoms of fever are continuous intermintent and can cause some serious complications such as cerebral malaria (brain malaria) and cause death. (3)

The treatment given is the radical treatment of malaria by killing all stages of parasites present in the human body. (4)One of the biggest challenges in malaria treatment efforts in Indonesia is the decrease in the efficacy of the use of several anti-malarial drugs, and there is even resistance to chloroquine. Since 2004 the main drug of choice for malaria has been a combination drug derived from Artemisinin known as Artemisinin-based 
Combination Therapy (ACT).(5) The artemisinin combination was chosen to improve the quality of malaria treatment that was already resistant to chloroquine where this artemisinin had a better therapeutic effect. (6)

The treatment program as an effort to overcome the malaria problem, aims to reduce morbidity, prevent death and cure patients. (7) Plasmodium vivax type malaria patients often do not comply with the rules for taking medication according to the treatment schedule and according to the prescribed dosage (8). Treatment failure was defined as the inability to clear malaria parasites or prevent recurrence after administration of antimalarial drugs. Many factors can contribute to treatment failure, namely wrong dosage, poor patients, non-adherent patients, poor drug quality and drug resistance. (9)

Based on the description above, this study aims to determine the use of antimalarial drugs in outpatient poly outpatients at the Hanura Public Health Center, Pesawaran Regency, based on the parameters of the right frequency, the right indication, the right drug, the right dose (4T).

\section{RESEARCH METHODS}

\section{Time and Place of Research}

This research was conducted in February 2020 at the UPT Puskesmas Hanura Hospital Pesawaran District.

\section{Types of research}

This research is a descriptive with purposive sampling method.. Purposive sampling, namely sampling based on certain considerations made by the researcher himself based on previously known characteristics or characteristics of the population that meet the inclusion and exclusion criteria.

\section{Population and Research Sample}

The population in this study were patients suffering from malaria in the outpatient clinic at the Hanura Public Health Center, Pesawaran District, in the JanuaryDecember 2018 period.

Determination of the sample using the Slovin formula.

$$
\mathbf{n}=\frac{\mathrm{N}}{1+\mathrm{N}(d)^{2}}
$$

Information :

$\mathrm{n} \quad=$ Number of samples

$\mathrm{N}=$ Total population

$\mathrm{d}=$ Level of confidence or precision $(d=0.1)$

The population obtained in this study are 1,535 population. Then the number of samples obtained from the population is 93 samples with positive diseases affected by malaria in the outpatient UPT Puskesmas Hanura, Pesawaran District.

\section{Research variable}

The independent variables in this study include medical records (age, gender, diagnosis) and prescription (use of antibiotics), while the dependent variable in this study is rationality based on $4 \mathrm{~T}$ indicators.(Right indication, Right Drug, Right Dosage, Right Frequency)

\section{Data collection}

The data collected in this study is by looking at the medical records of patients diagnosed with uncomplicated malaria at the Hanura Public Health Center, Pesawaran Regency.

\section{Data analysis}

Data analysis conducted in this study, the study used descriptive analysis, which included patient characteristics (age, gender, doctor's diagnosis and distribution of malaria drug use). The data obtained were analyzed descriptively qualitatively, then the data was tabulated and the results of the research could be assessed for accuracy based on $4 \mathrm{~T}$ criteria.(Right 
indication, Right Drug, Right Dosage, Right Frequency)

\section{RESULTS AND DISCUSSION}

The subjects of this study were outpatients with a diagnosis of Malaria in the January-December 2018 period at the Hanura Public Health Center, Pesawaran Regency. The number of samples taken based on the calculation results of 93 samples from medical records and prescriptions. Patient characteristics in this study were based on age, gender, body weight and Plasmodium.

\section{Patient Characteristics Based on Age}

Table 1 Characteristics by Age

\begin{tabular}{|c|c|c|c|}
\hline No. & Age Group & total & Percentage \% \\
\hline 1 & $0-5$ years & 7 & $7.53 \%$ \\
\hline 2 & 5-11 years & 13 & $13.98 \%$ \\
\hline 3 & $12-16$ years & 9 & $9.68 \%$ \\
\hline 4 & 17-25 years & 6 & $6.45 \%$ \\
\hline 5 & $26-35$ years & 4 & $4.30 \%$ \\
\hline 6 & $36-45$ years & 6 & $6.45 \%$ \\
\hline 7 & $46-55$ years & 5 & $5.38 \%$ \\
\hline 8 & $56-65$ years & 39 & $41.93 \%$ \\
\hline 9 & 65 - and above & 4 & $4.30 \%$ \\
\hline \multicolumn{2}{|r|}{ Total } & 93 & $100 \%$ \\
\hline
\end{tabular}

Based on the research conducted, the characteristics of patients affected by malaria were positive, based on the age of $0-5$ years there were 7 patients or $7.53 \%$, aged 5-11 years there were 13 patients or $13.98 \%$, aged $12-16$ years there were 9 patients or $9.68 \%$, aged $17-25$ years there were 6 patients or $6.45 \%$, aged $26-35$ years there were 4 patients or $4.30 \%$, ages 36-45 there were 6 patients or $6.45 \%$, ages $46-55$ there were 5 patients or $5.38 \%$, aged $56-65$ there were 39 patients or $41.93 \%$, aged 65 and over there were 4 patients or $4.30 \%$. The higher prevalence of malaria cases experienced by the age range 56-65 years. A similar study was conducted by (Novia Akwalia Rumagit et al, 2013) with the highest percentage of male patients with 44 cases of $64.7 \%$ (7). According to research related to the relationship of age to malaria by (Munizar, 2015) showed that there was a significant relationship between age and malaria ( $p$ value $=$ 0.002 ). This is because the age group is a group where this age allows to work and travel outside the house so that it is more likely to be in contact with the malaria vector. Therefore the incidence of malaria ranges in the ages of $56-65$ years compared to other ages (8).

2. Patient Characteristics Based on
Gender

Table 2 Characteristics of patients by sex

\begin{tabular}{|c|c|c|c|}
\hline No. & Gender & total & $\begin{array}{c}\text { Percentage } \\
\mathbf{\%}\end{array}$ \\
\hline 1 & Women & 21 & $22.59 \%$ \\
\hline 2 & Male & 72 & $77.41 \%$ \\
\hline & Total & $\mathbf{9 3}$ & $\mathbf{1 0 0 \%}$ \\
\hline
\end{tabular}

Based on the research conducted, the patient characteristics based on the sex of 93 malaria patients were female patients were 21 or $22.59 \%$, male patients were 72 patients or $77.41 \%$. Based on the table above, it shows that male patients who suffer from malaria are more than women, namely 72 out of 93 cases, as many as $77,41 \%$. A similar study was conducted by (Novia Akwila Rugmita et al, 2013) with the results that the highest percentage of patients with malaria was male patients with 44 cases or $64.7 \%$. According to research related to the relationship of sex to malaria by (Ferlia, 2014), it was found that there was a significant relationship between sex and malaria ( $p$ value $=0$,

3. Patient Characteristics Based on the Plasmodium group

Table 3 characteristics of the plasmodium group

\begin{tabular}{|c|c|c|c|}
\hline No. & $\begin{array}{c}\text { Plasmodium } \\
\text { group }\end{array}$ & total & Percentage \% \\
\hline $\mathbf{1}$ & $\begin{array}{c}\text { Plasmodium } \\
\text { falciparum }\end{array}$ & 14 & $15.05 \%$ \\
\hline $\mathbf{2}$ & $\begin{array}{c}\text { Plasmodium } \\
\text { vivax }\end{array}$ & 79 & $84.95 \%$ \\
\hline & Total & $\mathbf{9 3}$ & $\mathbf{1 0 0 \%}$ \\
\hline
\end{tabular}

Based on the research conducted, the characteristics based on the diagnosis (Table 3) of the plasmodium group of 93 malaria patients, there were 14 
plasmodium falciparum patients of $15.05 \%$, and 79 plasmodium vivax patients of $84.95 \%$. Based on the table above, it shows that the highest percentage of cases is Splasmodium vivax with a total of 79 cases, $84,95 \%$ of 93 cases. A similar study was conducted by (Novia Akwila Rumagit et al, 2013) with different results where the highest percentage was caused by plasmodium falciparum as many as 45 cases or $66.2 \%$. This is in accordance with the theory that plasmodium vivax reproduces well and has the potential to make contact with humans and transmit malaria, which is supported because of environmental factors such as rain, temperature, humidity,

\section{Evaluation of the Use of Antimalarial Drugs}

To find out the rational use of drugs can be seen from several criteria. The criteria used in evaluating the use of antimalarial drugs in this study were 4T (Right indication, Right Drug, Right Dosage, Right Frequency)

\section{Right Indication}

Table 4 Accuracy of Indication

\begin{tabular}{|c|c|c|c|c|}
\hline No. & $\begin{array}{c}\text { Right } \\
\text { Indication }\end{array}$ & Case Number & total & $\begin{array}{c}\text { Percentage } \\
\%\end{array}$ \\
\hline 1 & Right & $01,02,03,04,05,06,07,08,09,10,11,12,13,14,15,16,17$, & 93 & $100 \%$ \\
& & $18,19,20,21,22,23,24,25,26,27,28,29,30,31,32,33,34$, & & \\
& & $35,36,37,38,39,40,41,42,43,44,45,46,47,48,49,50,51$, & & \\
& & $52,53,54,55,56,57,58,59,60,61,62,63,64,65,66,67,68$, & & \\
& & $69,70,71,72,73,74,75,76,77,78,79,80,81,82,83,84,85$, & & \\
\hline 2 & Not & $86,87,88,89,90,91,92,93$ & 0 & $0 \%$ \\
\hline & Right & & & \\
\hline
\end{tabular}

Based on the accuracy of the indications (Table 4) shows that the accuracy of the indications for cases of Malaria Treatment at the Hanura Public Health Center UPT for the period January-December 2018, the correct indication is as many as 93 cases or $100 \%$. The $100 \%$ accuracy of the indication is due to the suitability of malaria drug administration as seen from the main diagnosis listed in the patient's medical record. A similar study was carried out by (Desinta et al., 2016) with the same results, namely $100 \%$ with a total of 83 cases of $100 \%$ due to the diagnosis studied and management using malaria drugs in accordance with the management of disease therapy and proper diagnosis.

\section{Right Medicine}

\section{Table 5 Drug Accuracy}

\begin{tabular}{|c|c|l|c|c|}
\hline No. & $\begin{array}{c}\text { Right } \\
\text { Medicine }\end{array}$ & \multicolumn{1}{|c|}{ Case Number } & total & $\begin{array}{c}\text { Percentage } \\
\%\end{array}$ \\
\hline 1 & Right & $01,02,03,04,05,06,07,08,09,10,11,12,13,14,15,16,17,18$, & 93 & $100 \%$ \\
& & $19,20,21,22,23,24,25,26,27,28,29,30,31,32,33,34,35,36$, & & \\
& & $37,38,39,40,41,42,43,44,45,46,47,48,49,50,51,52,53,54$, & & \\
& & $55,56,57,58,59,60,61,62,63,64,65,66,67,68,69,70,71,72$, & & \\
& & $73,74,75,76,77,78,79,80,81,82,83,84,85,86,87,88,89,90$, & & \\
\hline 2 & Incorrect & - & & 0 \\
\hline & & Total & 93 & $100 \%$ \\
\hline
\end{tabular}

Based on the accuracy of the drug (Table 5 ), it shows that the correct accuracy of the drug for malaria cases at the Hanura Public Health Center for the January-
December 2018 period was 93 cases at $100 \%$. It is said that the drug is right because the DHP-Frimal $360 \mathrm{mg}$ and Primakuin $15 \mathrm{mg}$ drugs given are in accordance with the standard references 
used, namely the WHO in 2012 and the 2017 Guidelines for Malaria Management. The accuracy of the drug is $100 \%$ due to the suitability of the administration of malaria drugs as seen from the main diagnosis listed in the patient's medical record. A similar study was carried out by (Desinta et al., 2016) with the same results, namely $100 \%$ with a total of 83 cases of $100 \%$ due to research on antimalarial drugs according to the list of drugs in the standard reference used.

\section{Right Dosage}

Table 6 Dosage Accuracy

\begin{tabular}{|l|c|c|c|c|}
\hline No. & $\begin{array}{c}\text { Right } \\
\text { Dosage }\end{array}$ & Case Number & total & $\begin{array}{c}\text { Percentage } \\
\%\end{array}$ \\
\hline 1 & Right & $01,02,03,05,07,08,09,10,11,12,13,14,15,16,17,18,19$, & 67 & $72.04 \%$ \\
& & $20,21,23,24,25,26,27,31,32,34,35,36,38,39,40,41,42$, & & \\
& & $43,45,47,48,49,52,53,54,57,60,64,65,66,67,68,69,70$, & & \\
& & $72,73,78,79,80,81,82,83,84,85,86,87,88,90,92,93$ & & $27.96 \%$ \\
\hline 2 & Incorrect & $04,06,22,28,29,30,33,37,44,46,50,51,55,56,58,59,61$, & 26 & \\
& & $62,63,71,74,75,76,77,89,91$ & & \\
\hline & & Total & 93 & $100 \%$ \\
\hline
\end{tabular}

Based on the dosage accuracy (Table 6) shows that the dosage accuracy for Malaria cases at the UPT Puskesmas Hanura Outpatient Installation for the January-December 2018 period, the correct dose was 67 out of 93 cases of $72.04 \%$ and the wrong dose was 26 of 93 cases. amounted to $27.96 \%$. The dosage accuracy of $72.04 \%$ was due to the suitability of the dosage of the drug given based on the reference to the Handbook for the Management of Malaria Cases in 2012. The inaccuracy of the dose was $27.96 \%$ due to the mismatch of the dosage being used excessively or inadequately. Inadequate doses can cause the therapeutic effect of the drug to not be achieved, while excessive doses can increase the toxic effects of DHP. Frimal $360 \mathrm{mg}$ and Primakuin $15 \mathrm{mg}$. Dose mismatch of $27,96 \%$ is due to the mismatch of the dose of drug selection so that the calculation of the dose is outside the reference used. Similar research was carried out by (Desinta et al, 2016) with different results, namely with a percentage of $100 \%$. that is because the place where the researcher is carried out has carried out treatment and administration of antimalarial drug doses appropriately.

4. Appropriate Frequency or Interval of Drug Administration

Table 7 Accuracy of Frequency or Interval of Drug Administration

\begin{tabular}{|l|l|l|c|c|}
\hline No. & $\begin{array}{c}\text { Precise Frequency } \\
\text { /interval }\end{array}$ & Case number & total & $\begin{array}{c}\text { Percentage } \\
\%\end{array}$ \\
\hline 1 & Right & $01,02,03,04,05,06,07,08,09,10,11,12,13,14,15,16$, & 92 & $98.92 \%$ \\
& & $17,18,19,20,21,22,23,24,25,26,27,28,29,31,32,33$, & & \\
& & $34,35,36,37,38,39,40,41,42,43,44,45,46,47,48$, & & \\
& & $49,50,51,52,53,54,55,56,57,58,59,60,61,62,63,64$, & & \\
& & $65,66,67,68,69,70,71,72,73,74,75,76,77,78,79,80$, & & \\
\hline 2 & Incorrect & $81,82,83,84,85,86,87,88,89,90,91,92,93$ & 1 & $1.08 \%$ \\
\hline & & 30 & 93 & $100 \%$ \\
\hline
\end{tabular}

Based on the exact interval of drug administration (Table 7), it shows that the accuracy of the interval for malaria cases in the UPT Puskesmas Hanura Outpatient 
Installation for the January-December 2018 period was 92 cases or $98.92 \%$. Interval inaccuracy was 1 case or $1.08 \%$. The accuracy of the time interval for drug administration was $98.92 \%$ due to the suitability of the frequency of administration of DHP-Frimal $360 \mathrm{mg}$ and $15 \mathrm{mg}$ Primakuin Drugs with reference to the Malaria Shirt Management Handbook. The right time interval increases the success in the right treatment, the right time interval also reduces the toxic effects in the body.

\section{CONCLUSIONS AND SUGGESTION}

\section{Conclusion}

Based on the results and discussion of research evaluating the use of antimalarial drugs at the Hanura Public Health Center UPT for the January-December 2018 period, the following conclusions can be drawn:

1. Patient characteristics were based on age, sex, body weight, and type of plasmodium in malaria patients in the outpatient installation at the UPT Puskesmas Hanura, namely based on age, there were 39 cases of malaria patients, mostly in the age range of $56-65$ years of $41.93 \%$. Based on gender, it was found that 72 cases occurred in malaria patients, mostly male patients were $77.41 \%$. Based on body weight, it was found that 79 cases occurred in malaria patients, more of which were exposed to Plasmodium Vivax by $84.95 \%$.

2. Evaluation of the use of antimalarial drugs based on accurate indications in malaria patients in the Outpatient Installation at the UPT Puskesmas Hanura was 93 cases or $100 \%$, Correct Drug was 93 cases or $100 \%$, Correct Dose was 67 cases or $72.04 \%$, and Correct Time Interval Drug administration was 92 cases or $98.92 \%$.

Vol 9 No. 1 Juni 2020

\section{Suggestion}

For further research that will conduct research on the Evaluation of the Use of Antimalarial Drugs, it is necessary to conduct research using retrospective methods. It is expected to study more sources and references related to malaria by looking at the patient's recovery which includes interviews with patients and doctors who write prescriptions.

\section{REFERENCES}

[1] Infodatin. Ri, Kementrian Kesehatan. Situasi Malaria Di Indonesia, Jakarta Selatan : Pusat Data Dan Informasi Kementrian Kesehatan Ri, 2014, Vol.1.

[2] Peraturan Presiden Republik Indonesia No 5 Tahun 2010 Tentang Rancangan Pembangunan Jangka Panjang. Ri, Presiden. Peraturan Presiden, Jakarta : S.N., 2010.

[3] Pedoman Tata Laksana Malaria. Ri, Menteri Kesehatan. Jakarta : Menteri Kesehatan Ri, 2013.

[4] Konsep Asuhan Kebidanan . Ri, Departemen Kesehatan. Jakarta : Departemen Kesehatan Ri, 2007.

[5] Primaquine For Preventing Relapse In People With Plasmodium Vivax Malaria Treated With Chloroquine. Galappaththy Gnl, Tharyan P, Kirubakaran R. Sri Lanka : Cochrane Library, 2013.

[6] Beberapa Faktor Resiko Kepatuhan Berobat Malaria Plasmodium Vivak. Wuryono, M.Arie. Banjarnegara : M.Arie Wuryono, 2005.

[7] Tingkat Kepatuhan Penderita Malaria Vivax Dalam Minum Obat Dan Faktor Yang Mempengaruhinya. Wuryanto, M. Arie. Banjar Negara : M. Arie Wuryanto, 2005.

[8] Adherence To Plasmodium Vivax Malaria Treatment In The Brazilian 
Amazon Region. A, Elza. Brazil : Elza A, 2010.
[9] Management Of Recurrent Plasmodium Vivax Malaria. Chu, Cindys. Afrika : Cindys Chu, 2016 